\title{
Age structure of female giant tiger prawns Penaeus monodon as indicated by neuronal lipofuscin concentration
}

\author{
Matt Sheehy ${ }^{1}$, Elizabeth Cameron ${ }^{1}$, Gay Marsden ${ }^{2}$, Juliet McGrath ${ }^{1}$
}

${ }^{1}$ Zoology Department, The University of Queensland, Brisbane, Queensland 4072, Australia

${ }^{2}$ Bribie Island Aquaculture Research Center, Department of Primary Industries, Bribie Island, Queensland 4507, Australia

\begin{abstract}
Fluorescent lipofuscin granules were found in the brains of both wild and pond-reared, mature, female giant tiger prawns Penaeus monodon. Lipofuscin concentrations, measured via image analysis of fluorescence micrographs, were significantly higher in the brains of 15.3 mo old pondreared prawns than in those 8.0 mo old. Cluster analysis of lipofuscin concentrations and morphometric data, when calibrated using the known-age pond-reared prawns, suggested that individuals from a wide range of ages, corresponding to 3 semi-annual cohorts at roughly 12, 18 and 24 mo of age, were present in the sample of mature wild females from the Cairns region of northern Queensland, Australia, in September 1993. As expected from earlier studies and as indicated here by discriminant function analyses, these apparent cohorts were more readily differentiated using lipofuscin concentration than either carapace length or weight. Use of lipofuscin concentration as a proxy measure of age suggested that growth of sampled prawns was similar to that previously reported for the species obtained using conventional methods. Lipofuscin concentrations were generally low and individual variation relatively high in this species, as is apparently the case for other prawns. However, this study suggests that age pigment can be useful for population age structure assessment in penaeids. The mixture of ages present in the wild female $P$. monodon population may indicate a potential source of variation in broodstock quality for future investigation.
\end{abstract}

KEY WORDS: Penaeus monodon · Age structure $\cdot$ Lipofuscin · Cluster analysis

\section{INTRODUCTION}

The giant tiger prawn Penaeus monodon does not provide a significant commercial fishery in Australia since it is caught only rarely, usually as a bycatch of other prawn fisheries (Grey et al. 1983). However, it is the major species used in Australian prawn mariculture operations. The broodstock supplying these farms presently comes entirely from the wild (Kailola et al. 1993). This is because pond-reared females have a longer latency period for egg production and rearing them to the optimal spawning age (>12 mo) requires additional culture facilities. Also, they require a special maturation diet which is not readily available (Primavera 1988). Wild gravid females are therefore in demand and may fetch high prices (Kailola et al. 1993).
There is considerable variation in spawning quality of wild females, both within catches and on a seasonal basis. Non-reproducing females are referred to as 'blanks'. It is desirable for broodstock collectors to be able to target particular times of year or size/age classes in order to minimize cost and effort while maximizing spawning success. The effects on egg quality and quantity of several variables including nutrition, light intensity, light quality, photoperiod, salinity and substrate have been evaluated previously (see Primavera 1988). One factor which seems likely to influence reproductive performance of wild spawners is their age. In the grooved tiger prawn Penaeus semisulcatus spawning rate reaches a peak at about $1 \mathrm{yr}$ of age with the output of older prawns declining (P. Crocos pers. comm.). In the northern waters of Australia, P. monodon spawning pulses occur in spring and autumn. 
Females may be more fecund in their second reproductive phase than their first, for example. However, the population dynamics of wild giant tiger prawns in Australian waters are not well understood (Kailola et al. 1993). Their general paucity in samples makes the application of traditional techniques for determination of age and growth rate, such as modal analysis of sizefrequency histograms and tag-recapture programs, particularly difficult. Some comparative information is, however, available from pond-rearing surveys (Jong et al. 1993). Age at maturity in wild $P$. monodon is thought to be about 10 mo (Primavera 1988).

In this study we used neuronal lipofuscin age pigment as an age index (Sheehy 1990a, 1992, Sheehy et al. 1994) for Penaeus monodon in order to provide insight into the age range of wild mature females being collected as spawners for Australian prawn farms. This might indicate a potential source of variation in wild broodstock quality for future investigation.

\section{MATERIALS AND METHODS}

Data collection. Mature female giant tiger prawns of unknown age, but potentially suitable as broodstock, were obtained live from inshore waters near Cairns, Australia $\left(16.55^{\circ} \mathrm{S}, 145.46^{\circ} \mathrm{E}\right)$ in September 1993. Known-age 8.0 and 15.3 mo old mature females were obtained from mariculture ponds at a nearby location, Mossman $\left(16.28^{\circ} \mathrm{S}, 145.23^{\circ} \mathrm{E}\right)$. Orbital carapace length and wet whole-body weight of each prawn was recorded. Each individual was immobilized in icy seawater and the brain (supra-oesophageal ganglion) carefully dissected and removed. To assist handling and orientation, all nerves originating from the brain were trimmed short except for the left circumoesophageal commissure. Brains were fixed for at least $5 \mathrm{~d}$ in $20 \%$ formalin in seawater with $16 \% \mathrm{w} / \mathrm{v}$ sucrose as an osmotic adjuster. Lipofuscin concentration, as a percentage volume fraction, was measured in the left olfactory lobe cell mass (see Sandeman et al. 1993) of each brain using fluorescence microscopy and image analysis techniques (Sheehy 1990b, Sheehy \& Wickins 1994).

Mathematical treatment of data. Data were graphically prepared and statistically analyzed using Sigma Plot 5.01 (Jandel Corporation) and SAS for Windows 6.08 (SAS Institute, Inc.) software. After F-testing for homogeneity of variance, appropriate $t$-tests were performed to assess differences in mean orbital carapace length, wet body weight and lipofuscin concentration between 8.0 and 15.3 mo old prawns. Cluster analysis was used to group pooled data from known- and unknown-age prawns. Based on the tripartite appearance of bivariate scatter plots of lipofuscin concentra- tion versus carapace length or body weight data, with reference to the clusters from known-age prawns, clustering routines were instructed to define 3 groups (putative age classes). All data were standardized to mean $=0$ and variance $=1$ prior to clustering. The results of 11 different clustering strategies available under the SAS Cluster procedure were compared. Once clusters were defined, these pooled classified data were used to calibrate discriminant functions (SAS Discrim procedure) based on each of the 3 variables in isolation or in paired combinations. Misclassifications of the resubstituted data into these discriminant functions provided an indication of the isolated or combined variables' usefulness for discerning the apparent age classes. A 1-tailed $t$-test was used to assess the difference between the mean lipofuscin concentration of the 15.3 mo old prawns and that of the cluster of wild prawns containing the highest lipofuscin levels.

\section{RESULTS}

Irregularly shaped yellow-fluorescing lipofuscin granules, up to a few microns in diameter, were associated with neurone cell bodies in the olfactory lobe and other cell masses throughout the brain in all prawns examined (Fig. 1). Mean carapace length, body weight and lipofuscin concentration of the 15.3 mo old group were significantly different $(\mathrm{p}<$ 0.05 ) from, and higher than, those of the 8.0 mo old group. There was no overlap between the 2 knownage groups in any of the 3 variables measured. Coefficients of variation for lipofuscin concentrations in the 8.0 and 15.3 mo old groups were $47.3 \%$ and $33.6 \%$, respectively. In bivariate plots of the relationships between lipofuscin concentration and carapace length or body weight (Fig. 2), the known-age group individuals formed 2 visually distinct clusters. When wild prawns of unknown age were plotted on the same graphs, a single individual was most closely associated with the 8.0 mo cluster while several individuals were most closely associated with the 15.3 mo cluster. The presence of a third distinct group of larger individuals with high lipofuscin concentrations was also indicated. The mean lipofuscin concentration of this group was significantly higher $(p<0.0005)$ than that of the 15.3 mo old reference group. All clustering strategies placed the prawns in the same 3 groups circled in Fig. 2. Based on this classification, discriminant functions using carapace length as the only predictor placed $26.1 \%$ of the prawns into the wrong group. Body weight, when used alone, resulted in $26.9 \%$ error. Error rate was similar when carapace length and body weight were used together $(23.3 \%)$. 


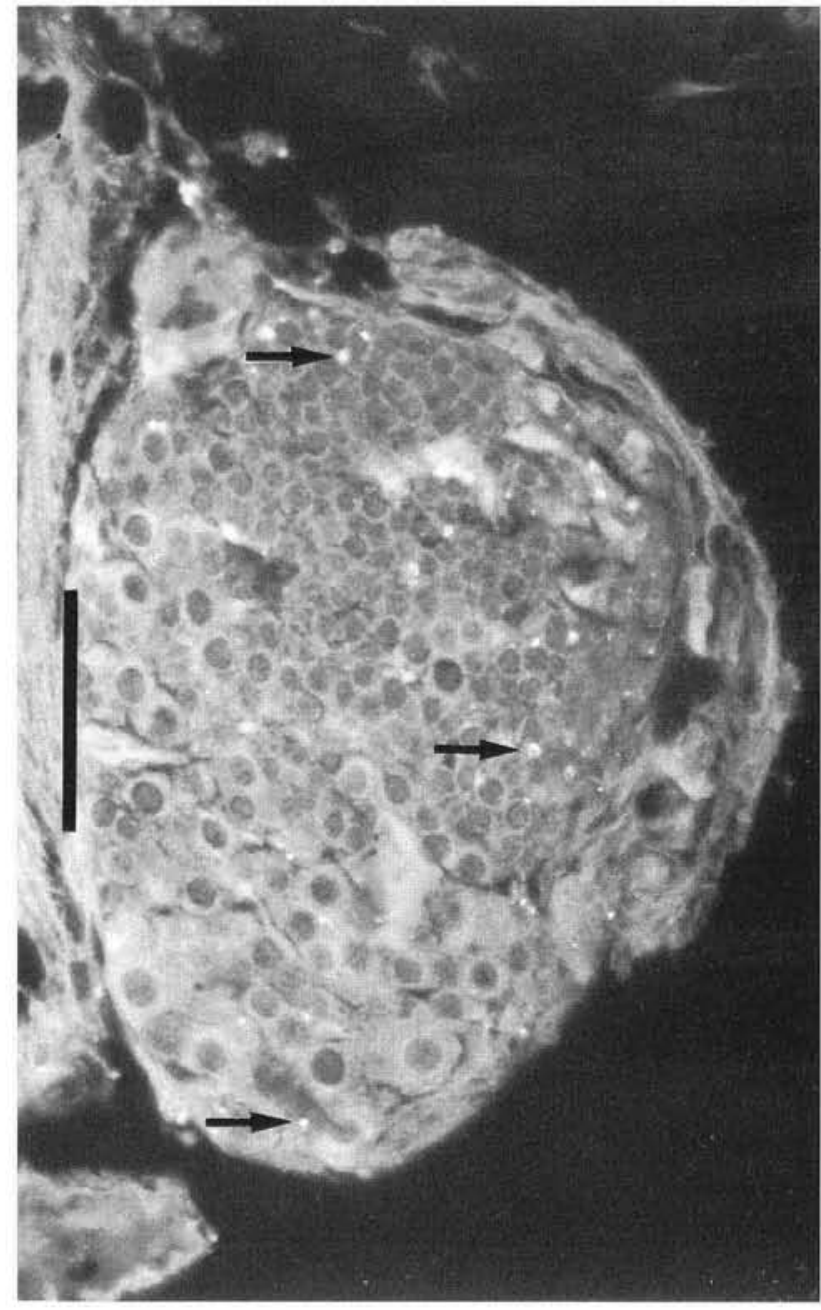

Fig. 1. Penaeus monodon. Enlargement of the left olfactory lobe cell mass in a $6 \mu \mathrm{m}$ thick unstained longitudinal brain section from a $\sim 2$ yr old wild female, showing yellowfluorescing lipofuscin aggregations (some arrowed) under $450 \mathrm{~nm}$ excitation. Scale bar $=25 \mu \mathrm{m}$

In contrast, only $4.4 \%$ of the prawns were misclassified using lipofuscin concentration as the only discriminator. When lipofuscin concentration was used in combination with either carapace length or body weight, all prawns were classified into their correct groups.

\section{DISCUSSION}

Lipofuscin was found in the nervous tissue of another penaeid, the brown tiger prawn Penaeus esculentus, in an earlier study (Sheehy 1990c). This is the first report of lipofuscin from P. monodon. It had a similar appearance to that in other Crustacea (Sheehy 1989, 1990c, Sheehy \& Wickins 1994). An absence of resolvable
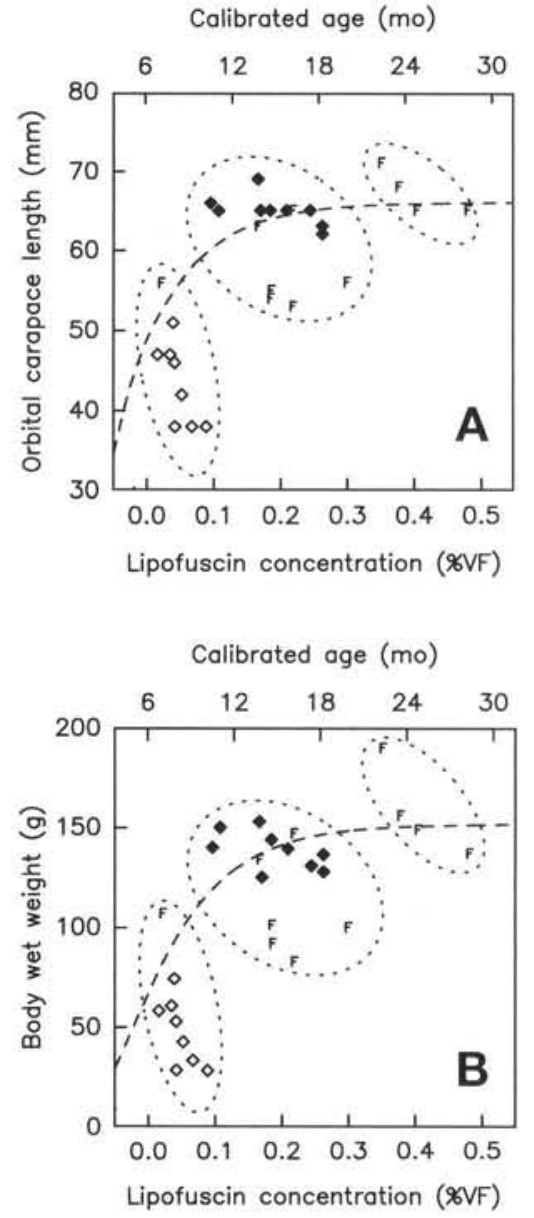

Fig. 2. Penaeus monodon. Relationships between lipofuscin concentration ( $\%$ volume fraction, VF) in the left olfactory lobe cell mass and (A) orbital carapace length, or (B) body wet weight, in adult female giant tiger prawns of known ages, $8.0(\diamond)$ or $15.3 \mathrm{mo}(\bullet)$, or from the field $(\mathrm{F})$. Dotted ovals enclose apparent age groups indicated by cluster analysis. The dashed curve in (A) represents a previous conventionally derived von Bertalanffy growth curve for female pond-reared P. monodon (Jong et al. 1993) and in (B) the weight-converted form of this curve based on the carapace length-weight relationship described for females by Motoh (1981)

lipofuscin was noted in 2 female $P$. monodon, both probably younger than those examined here (Sheehy 1990c). Maximum lipofuscin concentrations previously measured in freshwater red-claw crayfish Cherax quadricarinatus of comparable chronological age to the prawns in the present study (Sheehy et al. 1994) and in western rock lobster Panulirus cygnus of unknown age from the field (Sheehy unpubl.) were an order of magnitude higher than those in P. monodon. Lipofuscin concentrations measured in the present study were at the lower limit of detection of the quantification technique. While the coefficient of variation in lipofuscin levels in 15.3 mo old prawns (33.6\%) was 
less than that of much younger C. quadricarinatus (6 mo) possessing similar lipofuscin levels (58\%) (Sheehy unpubl.), it was relatively high when compared to that of crayfish of similar chronological age $(18.4 \%)$. This had the effect that lipofuscin was not able to resolve ages as finely in $P$. monodon as in the crayfish. The general paucity of lipofuscin in penaeids has already been noted (Sheehy 1990c), but the reason for this remains uncertain.

Nevertheless, lipofuscin concentration was still useful for discriminating between semi-annual age groups in Penaeus monodon. Pond-reared prawns 15.3 mo of age had measurably higher brain lipofuscin concentrations than 8.0 mo old individuals, confirming that lipofuscin accumulates with age in $P$. monodon as for many other species. Lipofuscin is a physiological, not chronological, age marker. Therefore, in the strictest sense, the wild and pond-reared prawns could only be compared in terms of their physiological age. However, the prawns came from the same geographical location and experienced comparable thermal regimes during development, so that similar physiological ages are likely to indicate similar chronological ages (Sheehy et al. 1994). The range of the lipofuscin data derived from the wild prawns, relative to that of the known-age pond-reared prawns, strongly suggested that the former were comprised of a wide range of ages. Given the range of the data, the apparent groupings, and the biannual nature of spawning of northern P. monodon, these wild females were probably derived from 3 semiannual cohorts.

Most of the wild females in the sample clustered with the 15.3 mo old pond-reared prawns. Closer inspection of this cluster showed that the wild prawns were displaced from the accompanying pond-reared individuals, with a slightly smaller average body size and a slightly greater mean lipofuscin level. This lipofuscin concentration corresponded to an average chronological age of about 18 mo and suggested that this group, collected in September (spring), originated from the spawning peak in the autumn of the previous year. This placed the cluster of larger females at an average age of about 2 yr, spawned in the spring of 1991. Lipofuscin concentration in the 8.0 mo old prawns was very low, as was that of the single wild female that clustered with this group. This prawn was probably between 8 and 12 mo of age. The first appearance of resolvable lipofuscin granules in Penaeus monodon is not likely to be much before $8 \mathrm{mo}$ of age. This is somewhat different to the Cherax spp. previously investigated (Sheehy $1990 \mathrm{a}, \mathrm{b})$, which are of roughly comparable longevity. In these, lipofuscin granules are visible at 2 mo.

The maximum estimated longevity of female Penaeus monodon is $2 \mathrm{yr}$ (see Solis 1988). The results of the present study, which included some very large individ- uals, support this. P. monodon is not a target fisheries species in Australian waters and, around Cairns, adults seem to be present in a habitat different from that of the other fished penaeids (N. Gribble pers. comm.). Therefore, there may be a relatively high proportion of older individuals present in the population. The occurrence of more than one mature cohort of prawns in the same sample is consistent with findings for other tiger prawns, for example P. semisulcatus (Somers \& Kirkwood 1991). It is also consistent with general models for tropical penaeid life histories, where there is interlocking between spring and autumn cohorts (Dall et al. 1990). The proportional representation of cohorts in the population will vary throughout the year. The present sample of field prawns included only large mature individuals, so that any 6 mo old cohort present in the population would not have been collected. In any case, lipofuscin would not have been detectable in these younger prawns using the present methods.

The difficulty in separating the oldest cohort by size alone is apparent from the data. Similar problems in separating size-frequency modes arising from older cohorts were noted by Somers \& Kirkwood (1991). Compression of the data onto the carapace length or weight axes resulted in inadequate discrimination between cohorts as indicated by a relatively high percentage of misclassification in the 1-dimensional discriminant function analyses of these predictors. On the other hand, use of lipofuscin by itself produced a very low percentage of misclassification and, when applied in a 2-dimensional analysis with either of the other 2 predictors, completely discriminated between the cohorts. In freshwater crayfish, lipofuscin concentration generally exhibits a lower level of individual variation than does body size and there is a smaller deceleration in accumulation rate than in growth rate, with advancing age (Sheehy 1992, Sheehy et al. 1994). From these findings it was proposed that lipofuscin might offer a completely new independent dimension for discriminating age cohorts. The results of the present study on Penaeus monodon support this proposition.

The von Bertalanffy curves depicted in Fig. 2 show that the trend in growth suggested by the present lipofuscin data is not widely different from that previously reported for Taiwanese pond-reared female Penaeus monodon (Jong et al. 1993).

This study demonstrates that neuronal lipofuscin can be useful for population age structure assessment in penaeids. The present results suggest the existence of 3 semiannual cohorts ( 2 year classes) of adult female Penaeus monodon in the spring population off Cairns. It remains to be tested whether this age structure can be linked to interseasonal and intrasample variation of giant tiger prawn broodstock performance. 
Acknowledgements. Wild giant tiger prawns were provided by $\mathrm{Mr}$ William Izzard, and pond-reared prawns were obtained from Sea Ranch Pty, Ltd, Mossman. Information provided by Drs P. Crocos (CSIRO, Cleveland) and Neil Gribble (DPI, Cairns) is gratefully acknowledged, as is the assistance of Dr Jack Greenwood and Mrs Lina Daddow. The project was funded by a Fisheries Research and Development Corporation collaborative grant to the Bribie Island Aquaculture Research Center.

\section{LITERATURE CITED}

Dall, W., Hill, B. J., Rothlisberg, P. C., Staples, D. J. (1990). The biology of the Penaeidae. In: Blaxter, J. H. S., Southward, A. J. (eds.) Advances in marine biology, Vol. 27. Academic Press, London

Grey, D. L., Dall, W., Baker, A. (1983). A guide to Australian penaeid prawns. Department of Primary Production of the Northern Territory, Darwin

Jong, K. J., Kou, K. H., Chen, S. N. (1993). Growth of Penaeus monodon Fabricius, 1798, in pond culture (Decapoda, Penaeidae). Crustaceana 65: 25-28

Kailola, P. J., Williams, M. J., Stewart, P. C., Reichelt, R. E., McNee, A., Grieve, C. (1993). Australian fisheries resources. Bureau of Resource Sciences and Fisheries Research and Development Corporation, Canberra

Primavera, J. H. (1988). Maturation, reproduction and broodstock technology. In: Biology and culture of Penaeus monodon. Brackish Aquaculture Information System, State-ofthe-art series no. 2. Aquaculture Department, Southeast Asian Fisheries Development Center, Tigbauan, Iloilo, Philippines, p. 37-58

Sandeman, D. C., Scholtz, G., Sandeman, R. E. (1993). Brain evolution in decapod Crustacea. J. exp. Zool. 265: $112-133$

This article was presented by G. F. Humphrey (Senior Editorial Advisor), Sydney, Australia
Sheehy, M. R. J. (1989). Crustacean brain lipofuscin: an examination of the morphological pigment in the freshwater crayfish Cherax cuspidatus. J. crustac. Biol. 9: 387-391

Sheehy, M. R. J. (1990a). The potential of morphological lipofuscin age-pigment as an index of crustacean age. Mar. Biol. 107: 439-442

Sheehy, M. R. J. (1990b). Individual variation in, and the effect of rearing temperature on, the concentration of fluorescent morphological lipofuscin in the brains of freshwater crayfish Cherax cuspidatus. Comp. Biochem. Physiol. 96A: 281-286

Sheehy, M. R. J. (1990c). The widespread occurrence of fluorescent morphological lipofuscin in the crustacean brain. J. crustac. Biol. 10: 613-622

Sheehy, M. R. J. (1992). Lipofuscin age-pigment accumulation in the brains of ageing field- and laboratory-reared crayfish Cherax quadricarinatus (von Martens) (Decapoda: Parastacidae). J. exp. mar. Biol. Ecol. 161: 79-89

Sheehy, M. R. J., Wickins, J. F. (1994). Lipofuscin age pigment in the brain of the European lobster, Homarus gammarus (L.). Microsc. Anal. 40: 23-25

Sheehy, M. R. J,, Greenwood, J. G., Fielder, D. F. (1994). More accurate chronological age determination of crustaceans from the field using the physiological age marker, lipofuscin. Mar. Biol. (in press)

Solis, N. B. (1988). Biology and ecology. In: Biology and culture of Penaeus monodon. Brackish Aquaculture Information System, State-of-the-art series no. 2. Aquaculture Department, Southeast Asian Fisheries Development Center, Tigbauan, Iloilo, Philippines, p. 3-36

Somers, I. F., Kirkwood, G. P. (1991). Population ecology of the grooved tiger prawn, Penaeus semisulcatus, in the northwestern Gulf of Carpentaria, Australia: growth, movement, age structure and infestation by the bopyrid parasite Epipenaeon ingens. Aust. J. mar. Freshwat. Res. 42: 349-367

Manuscript first received: July 13, 1994

Revised version accepted: September 15, 1994 